\title{
Cooperação intermunicipal na bacia do rio Paraopeba
}

\author{
Fernanda Matos \\ Centro Universitário UNA/MG \\ Reinaldo Dias \\ Universidade Presbiteriana Mackenzie
}

Neste artigo aborda-se o processo da descentralização do poder da esfera federal para o nível local, a responsabilidade dos consórcios e os fatores que dificultam e facilitam a cooperação intermunicipal. Os consórcios têm se mostrado uma alternativa para o gerenciamento das atribuições municipais. Este modelo gerencial propõe a participação de todos os atores sociais no gerenciamento das questões de interesse comum. O trabalho fornece uma visão geral sobre a cooperação intermunicipal, em especial na bacia do rio Paraopeba - Minas Gerais, Brasil —, a partir da análise de questionários direcionados aos gestores dos municípios. Evidencia-se uma abertura por parte dos municípios à participação em consórcios, considerando que 83\% dos municípios da bacia fazem parte de um ou mais tipos de arranjos intermunicipais e, também, a necessidade de desenvolvimento de ações para melhorar e/ou apoiar a cooperação entre os municípios.

Palavras-chave: municípios; parcerias; consórcio; associação; comitê.

\section{Cooperación intermunicipal en la cuenca del río Paraopeba}

Este artículo aborda el proceso de descentralización del poder del nivel federal a local, la responsabilidad de los consorcios y los factores que dificultan y facilitar la cooperación intermunicipal Consorcios han sido una alternativa para el manejo de las funciones municipales. Este modelo de gestión propone la participación de todos los actores sociales en la gestión de los asuntos de interés común. El documento proporciona una visión general de la cooperación inter-municipal, especialmente en la cuenca del río Paraopeba - Minas Gerais, Brasil — a partir del análisis de los cuestionarios dirigidos a los administradores de los municipios. Evidenciando una apertura por parte de los municipios para que participen en consorcios, mientras que el $83 \%$ de los municipios de la cuenca son parte de uno o más tipos de acuerdos intermunicipales, así como la necesidad de desarrollar acciones para mejorar y/o apoyar la cooperación entre municipios.

Palabras clave: municipios; asociaciones; consorcio; asociación; comité.

Artigo recebido em 16 ago. 2011 e aceito em 18 jul. 2012. 


\section{Intermunicipal cooperation in Paraopeba river basin}

This article discusses the process of decentralization of power from the federal to the local level, the consortia responsibilities and the factors that complicate and facilitate the inter-municipal cooperation. Consortia have been shown to be an alternative for managing municipal assignments. This managerial model proposes the participation of all social actors in the management of issues of common interest. The work provides an overview of the inter-municipal cooperation, in particular in the basin of Paraopeba - Minas Gerais, Brazil - from the analysis of questionnaires targeted at managers of municipalities. Evidencing an openness on the part of local participation in consortia, whereas $83 \%$ of the municipalities of the basin, part of one or more types of inter-municipal arrangements, and also the need to develop actions to improve and/or support cooperation between municipalities.

KeY wORDs: municipalities; partnerships; consortium; association; committee.

\section{Introdução}

A Constituição Federal de 1988 fortaleceu o papel dos municípios e redefiniu suas responsabilidades. E, na busca de alternativas de gerenciamento, os governos locais vêm transferindo suas responsabilidades para associações e fundações na forma de parcerias entre sociedade e Estado. Essas parcerias passam a prover os serviços públicos, sociais e científicos, a fim de torná-los mais ágeis e eficazes no atendimento das necessidades da população (Bresser-Pereira, 1998).

De acordo com Almeida e colaboradores (2009), os consórcios possibilitam a reunião de esforços em torno de problemas comuns aos municípios. Esses arranjos institucionais atuam em variadas esferas de interesse, tais como saúde, turismo, tratamento e destinação de resíduos sólidos, e em ações de saneamento básico, de habitação, bem como no gerenciamento de recursos hídricos (IBGE, 2008).

Este artigo apresenta uma reflexão sobre o desenvolvimento das cooperações intermunicipais, sobretudo na bacia do rio Paraopeba (MG). O objetivo é discutir as responsabilidades dos consórcios e os fatores que facilitam e dificultam a cooperação intermunicipal. A partir de uma revisão bibliográfica, conceitua-se e explica-se o surgimento da expressão consórcio intermunicipal e descreve-se de forma geral sua organização. Finalmente é elaborada a análise dos questionários semiestruturados direcionados aos gestores dos 48 municípios pertencentes à bacia do rio Paraopeba com a intenção de identificar a formação de cooperações intermunicipais, bem como as motivações da participação e a percepção dos representantes públicos sobre dificuldades, facilitadores e ações para fomentar a cooperação intermunicipal.

\section{Cooperação intermunicipal}

A cooperação internacional tem suas origens após a Segunda Guerra Mundial como um produto do contexto dos países europeus, fragilizados em suas estruturas políticas e econômicosociais. Esta aproximação traduziu-se numa reconciliação entre as nações e conduziu ao surgimento da tipologia de cooperação - a cooperação intermunicipal (Xavier, 2000). 
Nesse contexto, a França, a Inglaterra e a Alemanha foram pioneiras no desenvolvimento e fomento das relações de cooperação intermunicipal. As ligações entre cidades são numerosas e assumem formas variadas: relações recíprocas, pactos de amizade, contratos, protocolos etc., derivando de diferentes motivações, objetivos e entendimento das políticas a serem assumidas. Tendo por base as principais preocupações nas áreas da saúde, da educação, do ambiente, da gestão e administração de municípios, o urbanismo e suas infraestruturas, o alívio da pobreza, os intercâmbios profissionais e culturais, o desenvolvimento social, a assistência técnica, a formação profissional, entre outras (Xavier, 2000; Ribeiro e Faria, 2009).

Embora se torne instrumento mais disseminado no final do século XX, a ideia de consorciamento é antiga, remontando à Constituição Paulista de 1891. Sua existência concreta ocorre na década de 1960, registrando-se como os mais antigos no estado de São Paulo os Consórcios de Promoção Social da região de Bauru (SP), criados na década de 1960, e o Consórcio de Desenvolvimento do Vale do Paraíba (SP) — Codivap, criado em 1970 (Junqueira, 1990).

Sua utilização como parte de uma estratégia de descentralização de políticas públicas ocorre nas décadas de 1980 e 1990, se colocando então como uma alternativa para racionalização do modelo de gestão (Cruz et al., 2009). No estado de São Paulo, o governador Franco Montoro (1983-86) "incentivou a criação e a implementação de consórcios de desenvolvimento microrregional e também os vinculados à produção de alimentos" (Cruz et al., 2009:2).

É nesse período que entre 1983 e 1986 registra-se o apogeu de criação dos consórcios, sendo também o de maior índice de mortalidade, "do total de 32, doze não conseguiram sobreviver" (Barros, 1995:61).

A Constituição Federal de 1988 constituiu um fato novo em termos de administração pública, pois, segundo Matias-Pereira (2010), a Constituição Federal definiu sistemas de gestão democrática em diversas áreas de atuação da administração pública, como os colegiados dos órgãos públicos, na área da previdência social, onde os interesses profissionais e previdenciários são discutidos e deliberados pelos trabalhadores (art. 10). E, ainda, o planejamento participativo, mediante a cooperação das associações representativas no planejamento municipal, como preceito a ser observado pelos municípios (art. 29, XII). Além da gestão democrática do ensino público na área da educação (art. 206, VI). Na área da saúde, através do sistema único que integra uma rede regionalizada e hierarquizada organizado com a participação da comunidade (art. 198). Esses diferentes tipos de conselhos apontam para a existência de um espaço público de composição plural e paritária entre Estado e sociedade civil de natureza deliberativa (Jacobi, 2009).

Os conselhos de políticas constituem "espaços públicos de composição plural e paritária entre Estado e sociedade civil, de natureza deliberativa, cuja função é formular e controlar a execução das políticas públicas setoriais" (Tatagiba, 2002:54). Os conselhos constituem um dos aspectos do controle social da administração pública, permitindo à população um maior acesso aos espaços de formulação, implementação e controle social das políticas públicas (Santos, 2010:13). Além disso, esses conselhos constituem arranjos constitucionais com feições novas, pois não são meramente comunitários, e também não são meramente estatais. 
Têm um caráter compartilhado na formulação, gestão, controle e avaliação das políticas públicas (Bucci, 2002:327-328).

Outra medida que aponta para um fortalecimento da gestão democrática tomada pela Constituição de 1988 foi ter dado início no art. 23, parágrafo único, ao estabelecimento de normas para a cooperação entre a União, estados e municípios incluindo acordos firmados entre entidades estatais, autárquicas ou paraestatais, sempre da mesma espécie, para realização dos objetivos comuns. Nesse artigo constitucional fica estabelecido que "Lei complementar fixará normas para a cooperação" (Brasil, 1988). Em 1990, no âmbito da saúde, as Leis nº 8.080/1990 e no 8.142/1990 definiram que os consórcios intermunicipais poderiam integrar o Sistema Único de Saúde (SUS).

Em junho de 1998, a Emenda Constitucional 19, no art. 241, passou a permitir a gestão associada dos serviços públicos (Brasil, 1988; Diniz, 2009). No entanto, o disposto no art. 241 ficou dependente de legislação complementar durante vários anos, o que ocorre somente em 2005 com a Lei de Consórcios Públicos, de no 11.107 (Brasil, 2005, art. 1ํ). Sua regulamentação só ocorreu em janeiro de 2007 com a publicação do Decreto no 6.017 que normatizou a constituição dos consórcios públicos no Brasil.

A difusão dos consórcios intermunicipais no Brasil ocorreu no contexto de reforma do Estado e incentivo à descentralização, como uma alternativa para viabilizar serviços públicos de qualidade ao cidadão-cliente e solucionar problemas que transcendem os limites territoriais do município (Strelec, 2011). Para Best (2011:78), "não é possível desassociar o boom de criação de consórcios na década de 1990 dos processos de redemocratização e descentralização política". É necessário considerar nesse contexto que "o consórcio é um mecanismo institucional relativamente simples, eficaz e democrático de colaboração intergovernamental" (Best, 2011:78).

A lei de consórcios públicos cria uma expectativa em relação à possibilidade de ser uma alternativa de gestão. Já era um dos instrumentos mais utilizados entre alguns municípios na busca de promover a cooperação, mesmo antes da criação da lei de consórcios. "E eram denominados consórcios intermunicipais, uma vez que na doutrina jurídica este instrumento era previsto entre entes da mesma natureza. Portanto, a participação de entidades de natureza distinta em um mesmo consórcio" passa a "diferenciar este novo diploma legal da visão doutrinária dominante, sendo então caracterizado como instrumento de cooperação federativa, podendo ser utilizado de forma horizontal e vertical" (Ramalho, 2009:93).

No entanto, conforme afirma Best (2011:27-28), embora ocorra uma melhoria na estrutura jurídico-institucional, tornando "mais robustos os arranjos cooperativos, são poucos os consórcios públicos estabelecidos no âmbito da lei, e poucos os consórcios intermunicipais que se adequaram à nova legislação".

Segundo Fernandes (2009), como âmbito específico de organização do Estado os municípios tornaram-se locais de elaboração de políticas públicas, projetos participativos e decisões compartilhadas com a opinião pública. Isso é decorrente tanto das novas relações institucionais entre as esferas municipal, estadual e federal, quanto do espaço democrático criado com as comunidades locais e suas representações sociais e políticas. Contudo, a crescente auto- 
nomia e responsabilidade não implicaram melhorias para dar suporte à execução das novas atribuições (Carvalho, 2007).

De acordo com o plano diretor de reforma do aparelho do Estado (Brasil, 1995), a composição da força de trabalho no setor público em 1992, no que se refere à sua distribuição entre as três esferas de governo, mostra que os estados empregavam praticamente a soma (49\%) do que empregavam municípios (26\%) e a União (25\%). Esse perfil de distribuição, que demonstra uma clara concentração no nível estadual, revela-se a princípio incoerente com a municipalização da execução de serviços, conforme dispõe o texto constitucional.

Alguns estados têm buscado formas alternativas de gestão, transferindo responsabilidades para associações e fundações na forma de parcerias, para tornar mais ágil o atendimento das necessidades do público a que devem satisfação (Almeida et al., 2009).

Em Minas, dos 853 municípios, 611 participam de algum tipo de articulação, apresentando um percentual maior que o nacional, ou seja, 71,63\% dos municípios. Desses, 129 estão associados por meio de consórcios intermunicipais, 557 participam de Comitês de bacia hidrográfica e 78 participam de outro tipo de associação/parceria. Com relação aos temas abordados nas articulações, 372 correspondem à disposição de resíduos sólidos; 530, à recuperação da qualidade dos recursos hídricos; 322 correspondem ao tratamento de esgoto doméstico; 354, à recuperação de áreas degradadas; e 34, a outros temas (IBGE, 2008).

De acordo com Carvalho (2007), o desenvolvimento do novo modelo de gestão de políticas públicas, com a formulação conjunta de políticas e programas governamentais, tem possibilitado a ampliação da oferta de serviços por parte dos municípios, a flexibilização de contratação de pessoal, a realização conjunta de obras e prestação de serviços e atividades, tanto temporárias como permanentes.

Segundo o IBGE (2002), consórcio intermunicipal é um acordo firmado entre municípios para a realização de objetivos de interesse comum. Um dos principais motivos para se criar um consórcio é a carência dos gestores locais, tanto de capacidade instalada, quanto de recursos financeiros e humanos, diante do desafio da descentralização. Outros motivos incluem a possibilidade de implementação de ações conjuntas, a possibilidade de articulação de pressão conjunta junto aos órgãos de governo e a capacidade de visão macro dos ecossistemas em termos de planejamento e intervenção.

Para Prates (2010), os consórcios públicos se constituem com a ideia de juntar forças para a realização de objetivos que cada um isoladamente não conseguiria, por sua fragilidade financeira ou de recursos humanos. O que não significa uma incapacidade municipal, mas sim "uma tentativa de se criar escalas físicas e financeiras a fim de realizar investimentos a um custo muito menor para cada município..." (Prates, 2010:9).

No entendimento de Caldas (2007:53), "consórcio é uma associação originada de algum tipo de interesse comum e voltada para resolver um problema comum dos entes pertencentes ao mesmo nível de governo (município-município)". Numa definição um pouco mais elaborada, Cruz (2009:2) define os consórcios como uma "forma de cooperação entre os municípios, destinados a solucionar problemas e obter resultados conjuntos de natureza superior às capacidades política, financeira e operacional individual de seus integrantes". 
Numa abordagem diferenciada, Laczynski (2012:30) argumenta que o governo federal não desempenha um papel exclusivo na redução das desigualdades entre os municípios; ocorre também que "a união dos municípios para a ampliação da oferta dos serviços públicos, para o apoio aos pequenos produtores e para o desenvolvimento regional mostra a capacidade dos consórcios intermunicipais trabalharem na diminuição da desigualdade".

Privilegiando o âmbito político de tomada de decisão, Dieguez (2011) considera que os consórcios intermunicipais podem ser vistos como uma arena política federativa de cooperação horizontal, voltada para a produção compartilhada de decisões sobre políticas públicas.

Num estudo comparativo transnacional sobre governança metropolitana realizado em seis países latino-americanos, ao analisar as principais características institucionais e organizacionais encontradas, Wilson, Spink e Ward (2011:26) destacam a abordagem técnica e gerencial dos consórcios se contrapondo ao aspecto democrático. Nesse estudo identificam que no cenário da governança local uma característica positiva do Brasil é a presença dos "acordos intermunicipais e consórcios usados para coordenar a infraestrutura ou colaborar na área de políticas públicas ambientais e sociais, tais como a saúde, e também o desenvolvimento econômico". Consideram que "esses arranjos parecem provocar um sentimento de identidade e apoio dos cidadãos locais mas, no entanto, sua abordagem é técnica e gerencial, ao invés de democrática na abordagem".

Segundo Diniz (2009), o processo de consorciamento tem início com a aprovação da lei municipal pelas câmaras locais dos municípios ingressantes, permitindo a participação do município no consórcio. Em seus modos de implantação, os consórcios podem ser um simples pacto entre prefeitos ou possuir personalidade jurídica própria, que conta com instâncias de direção, tais como um Conselho de Administração, composto pelos prefeitos dos municípios integrantes, regido por estatuto próprio. E os recursos financeiros dos consórcios podem ser de origem de contribuições dos municípios participantes ou de receitas geradas por atividades do consórcio (IBGE, 2002).

O consórcio deve ser formado como pessoa jurídica de direito privado devendo ser regido pelos princípios básicos da administração pública. Tendo em vista a participação da pessoa pública em sua criação, os recursos que irá administrar são públicos, advindos dos municípios, além da possibilidade de recebimento do estado e da união e de outras fontes participantes (Diniz, 2009).

O Cepam (2001) esclarece que os consórcios não são entidades supramunicipais, ou seja, acima das entidades municipais que os integram, e também não possuem autonomia política. São organizações de auxílio e de cooperação com as unidades que os integram, formulando políticas e diretrizes intermunicipais, gerenciando planos e programas e realizando obras e serviços de interesse intermunicipal.

\section{A bacia hidrográfica do rio Paraopeba}

A bacia hidrográfica do rio Paraopeba está situada a sudeste do estado de Minas Gerais, abrangendo uma área de $13.643 \mathrm{~km}^{2}$. O rio é um dos mais importantes tributários do rio São 
Francisco, tem suas nascentes ao sul do município de Cristiano Otoni, percorrendo aproximadamente $510 \mathrm{~km}$ até sua foz no lago da represa de Três Marias, no município de Felixlândia. Possui uma área que corresponde a $2,5 \%$ da área total do estado de Minas Gerais. Segundo o IBGE (2007), aproximadamente 2.023.468 pessoas vivem nos 48 municípios pertencentes à bacia, mas apenas 1.476.020 estão diretamente inseridas nela.

A bacia é formada pelos municípios de Belo Vale, Betim, Bonfim, Brumadinho, Cachoeira da Prata, Caetanópolis, Casa Grande, Congonhas, Conselheiro Lafaiete, Contagem, Cristiano Otoni, Crucilândia, Curvelo, Desterro de Entre Rios, Entre Rios de Minas, Esmeraldas, Felixlândia, Florestal, Fortuna de Minas, Ibirité, Igarapé, Inhaúma, Itatiaiuçu, Itaúna, Itaverava, Jeceaba, Juatuba, Lagoa Dourada, Maravilhas, Mário Campos, Mateus Leme, Moeda, Ouro Branco, Ouro Preto, Papagaios, Pará de Minas, Paraopeba, Pequi, Piedade dos Gerais, Pompéu, Queluzito, Resende Costa, Rio Manso, São Brás do Suaçuí, São Joaquim de Bicas, São José da Varginha, Sarzedo, Sete Lagoas.

\section{Resultados}

Os primeiros contatos nos municípios foram realizados no final do mês de agosto e início do mês de setembro de 2010. O último questionário foi obtido no início do mês de março de 2011. Dos 48 municípios da bacia do rio Paraopeba, dois municípios não enviaram resposta ao questionário (Itatiaiuçu e São José de Varginha) alegando possuírem outras prioridades que os impossibilitavam destinar tempo para responder às questões, seja por e-mail, telefone ou pessoalmente. Portanto, a análise foi realizada com base nas respostas de 46 dos 48 municípios da bacia hidrográfica do rio Paraopeba.

O município que apresenta menor população da bacia, segundo o IBGE (2010), é Queluzito, com apenas 1.866 habitantes; seguido por Casa Grande, com 2.242 habitantes; Fortuna de Minas, com 2.701 habitantes, e São Brás do Suaçuí, com 3.512. E os municípios da bacia que apresentam maior população são os municípios de Ibirité, com 159.026 habitantes; Sete Lagoas, com 214.071 habitantes; Betim, com 377.547 e Contagem, com 603.048 habitantes. Desses últimos, apenas Sete Lagoas não faz parte da Região Metropolitana de Belo Horizonte, mas faz parte do Colar Metropolitano, que é composto pelos municípios do entorno da Região Metropolitana atingidos pelo processo de metropolização (Agência Metropolitana, 2011).

Dos 46 municípios que responderam ao questionário de pesquisa, 38 municípios, ou seja, 83\%, informaram participar de algum tipo de parceria com outros municípios para a realização de atividades conjuntas. E apenas oito municípios, o equivalente a 17\% do total, não participam de nenhum tipo de consórcio intermunicipal.

Os 38 municípios que informaram participar de algum tipo de consórcio citaram a participação em 22 instituições intermunicipais, formando 73 parcerias. Isso se deve ao fato de que 18 deles disseram integrar mais de um tipo de acordo intermunicipal, como o município de Congonhas, que informou participar de cinco consórcios, seguido por Brumadinho, Conselheiro Lafaiete e Ouro Branco, que citaram a formação de quatro arranjos institucionais cada. 
A tabela a seguir mostra a relação dos consórcios citados pelos municípios com o número de consorciados e sua relação com a bacia hidrográfica do rio Paraopeba, comparando-os ao número de participações citadas pelos municípios. Conforme o IBGE (2008), há outros arranjos institucionais que atuam na área da saúde, turismo, tratamento e destinação de resíduos sólidos, ações de saneamento básico e habitação, bem como o gerenciamento de recursos hídricos.

Tabela

\section{Relação de municípios $\times$ consórcios}

\begin{tabular}{|lccc|}
\hline \multicolumn{1}{|c}{ Consórcios } & № de municípios participantes & $\begin{array}{c}\text { № de municípios do consórcio } \\
\text { que pertencem à bacia do } \\
\text { Paraopeba }\end{array}$ & $\begin{array}{c}\text { № de municípios que } \\
\text { informaram participar do } \\
\text { consórcio }\end{array}$ \\
\hline Comparesolub & 9 & 9 & 7 \\
Codap & 7 & 7 & 7 \\
Cisap & 16 & 11 & 5 \\
Cismep & 16 & 15 & 4 \\
Cispará & 11 & 6 & 4 \\
Amalpa & 20 & 12 & 3 \\
Ecotres & 3 & 3 & 3 \\
CBH Pará & 35 & 9 & 2 \\
Cismisel & 11 & 6 & 2 \\
Coderi & 5 & 1 & 1 \\
Cisru & 51 & 13 & 1 \\
Amav & 20 & 9 & 1 \\
Ameco & 13 & 10 & 1 \\
Comlago & 8 & 2 & 1 \\
Cons. Pampulha & 2 & 1 & 1 \\
Cismev & 10 & 2 & 1 \\
Circuito Verde & 9 & 5 & 1 \\
Granbel & 34 & 13 & 1 \\
\hline
\end{tabular}

Fonte: Elaboração dos autores.

Segundo Barros (1995), a formação de arranjos intermunicipais e seus compromissos possuem uma coerência de prioridade de intervenção, aparecendo em primeiro lugar as políticas públicas básicas (desenvolvimento regional, meio ambiente, saneamento, controle de enchentes, entre outros), seguidas das políticas sociais (saúde, alimentação e assistência social), obras e equipamentos (pavimentações, construções, fornecimento de materiais) e serviços de apoio (projetos esporádicos de informática, turismo e lazer). Isso pode ser evidenciado no gráfico 1. 
Gráfico 1

\section{Tipos de associações formadas pelos municípios da bacia}

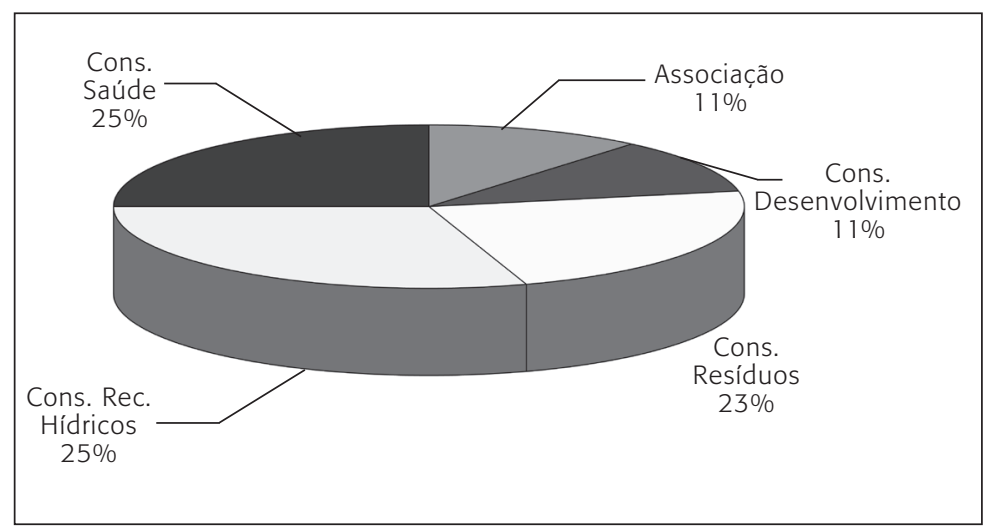

Fonte: Elaboração dos autores.

Como demonstra o gráfico 1, segundo informações dos próprios municípios, 11 deles (11\%) participam em associações entre municípios; outros 11 (11\%) compõem consórcios de desenvolvimento regional; 17 (23\%) participam de consórcios de resíduos sólidos; 18 (25\%) integram consórcios para a prestação de serviços de saúde e 22 (30\%) participam de arranjos para gerenciamento de recursos hídricos.

O gráfico 2 demonstra a representatividade dos arranjos intermunicipais formados, a partir das informações fornecidas pelos representantes públicos dos municípios pesquisados. $\mathrm{Na}$ área de gerenciamento de recursos hídricos, 15 municípios informaram sua participação no Consórcio Intermunicipal da Bacia Hidrográfica do Rio Paraopeba (Cibapar); três estão ligados ao Comitê de Bacia Hidrográfica do Rio Paraopeba; dois estão ligados ao Comitê de Bacia Hidrográfica do Rio Pará (CBH Pará); um participa do Consórcio Pampulha; e outro município participa do Comlago.

Na área de tratamento e destinação final de resíduos sólidos, sete municípios informaram participar do Comparesolub; três participam do Ecotres; e outros sete municípios disseram participar de consórcios para "triagem e compostagem de lixo", "aterro", "dar destino legal aos resíduos de saúde" (porém, os representantes não souberam informar o nome do consórcio).

Com relação aos consórcios na área de saúde, cinco municípios disseram participar do Cisap; outros cinco integram o Cismep; quatro fazem parte do Cispará; dois participam do Cismisel. Os consórcios Cismev e Cisru receberam, cada um, apenas uma indicação de participação. Segundo o Cosens-MG (2010), esses consórcios são mantidos com verba do SUS e repasses mensais das prefeituras consorciadas.

Os consórcios de desenvolvimento regional Coderi e Codap foram citados, no que diz respeito à participação, respectivamente, por um município e sete municípios. No que concerne às associações regionais, a participação na Amalpa foi citada por três municípios; e as associações Amav, Ameco, Iclei, Circuito Verde e Granbel receberam apenas uma indicação cada. 
Gráfico 2

Participação dos municípios da bacia por consórcio

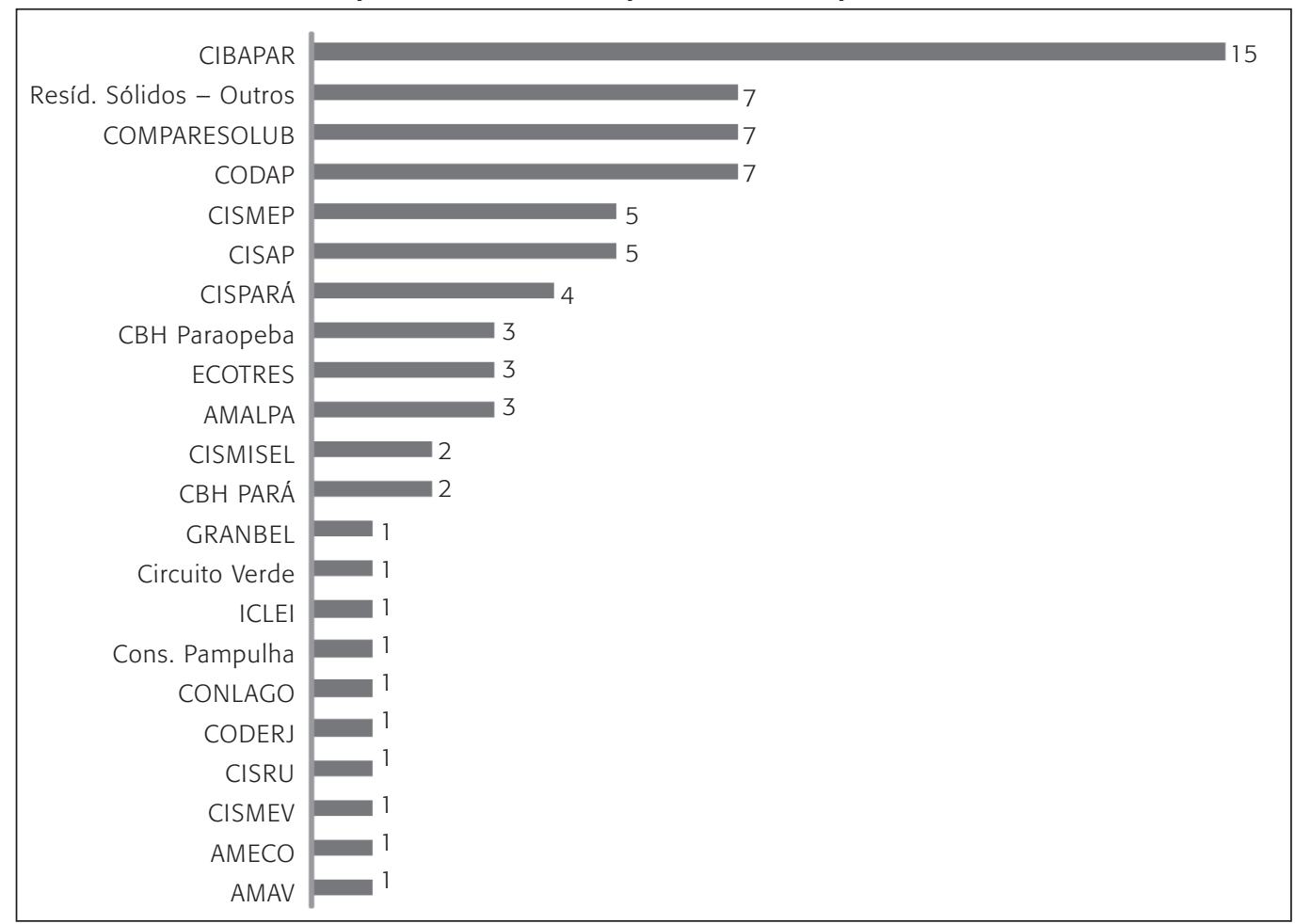

Fonte: Elaboração dos autores.

\section{As cooperações destacadas}

Codap - Consórcio Público para Desenvolvimento do Alto Paraopeba, entidade que reúne os municípios de Belo Vale, Congonhas, Conselheiro Lafaiete, Entre Rios de Minas, Jeceaba, Ouro Branco e São Brás do Suaçuí, todos localizados na região do Alto Paraopeba, em Minas Gerais. O Codap é o primeiro consórcio público do país e um dos únicos do Brasil, com atuação regional e multissetorial. Por meio do Codap são desenvolvidos projetos direcionados ao desenvolvimento regional sustentável, ao aperfeiçoamento das gestões administrativas dos consorciados, além de políticas públicas que beneficiam a região (Codap, 2010). Todos os municípios desse consórcio mencionaram sua participação e fazem parte da relação de municípios da bacia do Paraopeba.

Cibapar e CBH-Paraopeba - Impulsionados pela Política Estadual de Recursos Hídricos, Lei no 11.504 de 20 de junho de 1994, os municípios de Betim, Bonfim, Brumadinho, Esmeraldas, Ibirité, Igarapé, Juatuba, Mateus Leme, representados pelos seus prefeitos, formalmente autorizados por suas respectivas Câmaras Municipais, em novembro de 1994 fundaram 
o Consórcio Intermunicipal da Bacia Hidrográfica do rio Paraopeba (Cibapar). O consórcio foi instituído sob a forma de sociedade civil sem fins econômicos, regendo-se pelas normas do Código Civil brasileiro e demais preceitos da legislação aplicável, pelo seu Estatuto e regulamentações.

Desde a sua constituição, o Consórcio incentivou e promoveu processos participativos, e uma das consequências dessa discussão foi a institucionalização do Comitê da Bacia Hidrográfica do Rio Paraopeba (CBH-Paraopeba), por meio do Decreto no 40.398, de 28 de maio de 1999. Criado "com a finalidade de promover, no âmbito da gestão de recursos hídricos, a viabilização técnica e econômico-financeira de programa de investimento e consolidação de políticas de estruturação urbana e regional, visando ao desenvolvimento sustentado da Bacia".

Comparesolub - O Consórcio Médio Paraopebano de Resíduos Sólidos Urbanos é formado por Betim, Brumadinho, Juatuba, Mário Campos, Mateus Leme, Ibirité, Igarapé, São Joaquim de Bicas e Sarzedo. O Consórcio tem como finalidade planejar e executar as atividades de interesse comum definidas pelo Consórcio na implantação, operação e utilização de aterro sanitário destinado à disposição correta dos resíduos sólidos domiciliares, comerciais (com características domiciliares) e públicos (derivados da limpeza urbana), atendendo a legislação pertinente (CMB, 2009).

Cisap - O Consórcio Intermunicipal de Saúde do Alto Paraopeba é formado por Belo Vale, Caranaíba, Casa Grande, Catas Altas da Noruega, Congonhas, Conselheiro Lafaiete, Desterro de Entre Rios, Entre Rios de Minas, Itaverava, Jeceaba, Lamim, Ouro Branco, Queluzito, Santana dos Montes, São Brás do Suaçuí, Senhora de Oliveira (Cosens-MG, 2010). Dos 16 municípios que formam o consórcio, 11 estão inseridos na bacia do Paraopeba, mas apenas cinco informaram sobre a consorciação (Casa Grande, Congonhas, Itaverava, Ouro Branco, Queluzito).

Cispará - O Consórcio Intermunicipal de Saúde do Alto do Rio Pará foi fundado em 1996 e atende às cidades de Conceição do Pará, Florestal, Igaratinga, Leandro Ferreira, Maravilhas, Onça de Pitangui, Papagaios, Pará de Minas, Pequi, Pitangui, São José da Varginha (Cosens-MG, 2010). Dos 11 municípios que formam o consórcio, seis estão inseridos na bacia do Paraopeba, mas apenas quatro informaram sobre a consorciação (Maravilhas, Pará de Minas, Papagaios, Pequi), um não mencionou sua participação (Florestal) e outro município não respondeu ao questionário (São José de Varginha).

Cismep - O Consórcio Intermunicipal de Saúde do Médio Paraopeba é composto pelos municípios de Betim, Bonfim, Brumadinho, Contagem, Crucilândia, Esmeraldas, Florestal, Igarapé, Itaguara, Juatuba, Mário Campos, Mateus Leme, Piedade dos Gerais, Rio Manso, São Joaquim de Bicas e São José de Varginha. O Consórcio foi criado em 1996 e a prestação de serviços teve início efetivamente em 2005. Ele surgiu da necessidade de oferecer à população da região acesso ao atendimento de média complexidade com qualidade e eficiência (Cismep, 2011). Dos 16 municípios que formam o consórcio, apenas um não está inserido na bacia do Paraopeba (Itaguara); porém, apenas quatro municípios informaram sobre a consorciação (Brumadinho, Crucilândia, Igarapé e São Joaquim de Bicas). Dez municípios não 
mencionaram sua participação e um município não respondeu ao questionário (São José de Varginha).

Ecotres - O Consórcio Intermunicipal de Tratamento de Resíduos Sólidos é formado pelos municípios de Congonhas, Conselheiro Lafaiete e Ouro Branco. A finalidade principal do consórcio é a implantação e administração do Aterro Sanitário Consorciado, do Incinerador de Resíduos Sólidos Hospitalares, da Usina de Tratamento de Resíduos Sólidos e da Usina de Compostagem, além do planejamento e da execução de projetos conjuntos destinados a promover, melhorar e controlar a coleta, transporte, armazenamento, tratamento, compostagem, destino final, reúso, reciclagem e monitoramento dos insumos, no que diz respeito aos resíduos sólidos em todas as suas modalidades (CMCL, 2005).

Amalpa - A Associação dos Municípios da Microrregião do Alto Paraopeba foi fundada em 1976, tendo como área de abrangência 20 municípios, a saber: Belo Vale, Brás Pires, Caranaíba, Casa Grande, Catas Altas da Noruega, Congonhas, Conselheiro Lafaiete, Cristiano Otoni, Desterro de Entre Rios, Entre Rios de Minas, Itaverava, Jeceaba, Lamim, Ouro Branco, Piranga, Queluzito, Rio Espera, Santana dos Montes, São Brás do Suaçuí e Senhora de Oliveira (Amalpa, 2011). Desses 20 participantes, 12 municípios estão inseridos na bacia do Paraopeba, mas apenas três citaram a consorciação (Conselheiro Lafaiete, Entre Rios de Minas e Itaúna), ou seja, nove municípios não informaram sua participação nesse consórcio (Belo Vale, Casa Grande, Congonhas, Cristiano Otoni, Desterro de Entre Rios, Itaverava, Jeceaba, Ouro Branco, Queluzito e São Brás do Suaçuí).

CBH-Pará - O Comitê da Bacia Hidrográfica do Rio Pará foi instituído com a finalidade de promover, no âmbito da gestão de recursos hídricos, a viabilização técnica e econômicofinanceira de programas de investimento e consolidação de políticas de estruturação urbana e regional, visando ao desenvolvimento sustentado da bacia. A bacia hidrográfica do rio Pará abrange Araújos, Bom Despacho, Carmo da Mata, Carmo do Cajuru, Carmópolis de Minas, Cláudio, Conceição do Pará, Divinópolis, Desterro de Entre Rios, Florestal, Formiga, Igaratinga, Itatiaiuçu, Itaguara, Itapecerica, Itaúna, Leandro Ferreira, Maravilhas, Martinho Campos, Nova Serrana, Oliveira, Onça do Pitangui, Papagaios, Pará de Minas, Passa Tempo, Pedra do Indaiá, Perdigão, Pitangui, Piracema, Pompéu, Resende Costa, Santo Antônio do Monte, São Francisco de Paula, São Gonçalo do Pará e São Sebastião do Oeste (Igam, 2011). Dos 35 municípios citados, nove também pertencem à bacia hidrográfica do rio Paraopeba, e, desses nove municípios, sete possuem cargos de membros titulares ou suplentes na lista de conselheiros do CBH-Pará (Desterro de Entre Rios, Florestal, Itaúna, Maravilhas, Pará de Minas, Pompeu e Resende Costa), mas apenas dois informaram sua participação (Desterro de Entre Rios e Pará de Minas).

Cismisel - O Consórcio Intermunicipal de Saúde da Microrregião de Sete Lagoas foi fundado em 1996 e é formado pelos municípios de Araçaí, Baldim, Cachoeira da Prata, Caetanópolis, Cordisburgo, Fortuna de Minas, Inhaúma, Jequitibá, Paraopeba, Santana de Pirapama e Sete Lagoas. Dos 11 municípios que compõem o consórcio, seis pertencem à bacia do Paraopeba (Cachoeira da Prata, Caetanópolis, Fortuna de Minas, Inhaúma, Paraopeba e Sete Lagoas), mas apenas um informou sobre a consorciação (Paraopeba). 
Cismev - O Consórcio Intermunicipal de Saúde do Médio Rio das Velhas, fundado em 1995, é formado pelos municípios de Augusto de Lima, Buenópolis, Corinto, Curvelo, Felixlândia, Inimutaba, Monjolos, Morro da Garça, Presidente Juscelino e Santo Hipólito. Dos 10 municípios que formam o consórcio, dois pertencem à bacia do Paraopeba (Curvelo e Felixlândia), mas apenas um informou sobre a consorciação (Felixlândia).

Consórcio Pampulha - O Consórcio de Recuperação da Bacia da Pampulha foi fundado pelas prefeituras de Belo Horizonte e Contagem em fevereiro de 2000. O objetivo é promover a integração entre os municípios, empresas públicas e privadas, organizações não governamentais, órgãos públicos, comunidades e demais instituições interessadas na proteção e recuperação da Bacia da Pampulha (CRBP, 2003).

Comlago - O Consórcio dos Municípios do Lago de Três Marias visa obter cooperação mútua entre seus partícipes e desses com a União e o Estado de Minas Gerais, na realização de interesses comuns atinentes ao desenvolvimento regional sustentável e de seus recursos hídricos e ambientais, notadamente o gerenciamento integrado e descentralizado da bacia hidrográfica do entorno da represa de Três Marias. É formado por Abaeté e Biquinhas, Felixlândia, Morada Nova de Minas, Paineiras, Pompéu, São Gonçalo do Abaeté, Três Marias (Comlago, 2009). Dos oito municípios que participam do consórcio, dois fazem parte da bacia do rio Paraopeba (Felixlândia e Pompéu), mas apenas um informou sobre a consorciação (Felixlândia).

Ameco - A Associação dos Municípios do Médio Centro-Oeste é formada por Bonfim, Carmópolis de Minas, Crucilândia, Florestal, Itatiaiuçu, Itaúna, Moeda, Onça de Pitangui, Pará de Minas, Piedade dos Gerais, Piracema, Rio Manso e São José da Varginha (Agência Minas, 2005). Dos 13 municípios participantes, 10 pertencem à bacia do rio Paraopeba (Bonfim, Crucilândia, Florestal, Itatiaiuçu, Itaúna, Moeda, Pará de Minas, Piedade dos Gerais, Rio Manso e São José da Varginha). Dois municípios não responderam à pesquisa (São José da Varginha e Itatiaiuçu) e, dos que responderam, apenas um citou a participação na associação (Moeda).

Amav - A Associação dos Municípios da Microrregião do Alto Rio das Velhas trabalha no sentido de fortalecer a gestão municipal e ampliar a capacidade administrativa, técnica e financeira dos municípios que a compõem. Ela é formada por Araçaí, Baldim, Cachoeira da Prata, Caetanópolis, Capim Branco, Cordisburgo, Fortuna de Minas, Funilândia, Inhaúma, Jaboticatubas, Jequitibá, Maravilhas, Matozinhos, Papagaios, Paraopeba, Pequi, Prudente de Morais, Santana de Pirapama, Santana do Riacho, Sete Lagoas e Taquaraçu de Minas (Amav, 2011). Dos 20 municípios associados, nove pertencem à bacia do Paraopeba (Cachoeira da Prata, Caetanópolis, Fortuna de Minas, Inhaúma, Maravilhas, Papagaios, Paraopeba, Pequi e Sete Lagoas), e apenas um informou sobre a consorciação (Inhaúma).

Cisru - O Consórcio Intermunicipal de Saúde da Rede de Urgência Centro Sul tem como finalidade desenvolver, em conjunto, ações e serviços de saúde, observados os preceitos que regem o SUS, especialmente no que tange ao gerenciamento dos serviços de urgência e emergência da Macrorregião Centro Sul do Estado de Minas Gerais. O consórcio é constituído pelos municípios de Alfredo Vasconcelos, Alto Rio Doce, Antônio Carlos, Barbacena, Barroso, 
Bom Sucesso, Capela Nova, Caranaíba, Carandaí, Casa Grande, Catas Altas da Nororuega, Cipotânea, Conceição da Barra de Minas, Congonhas, Conselheiro Lafaiete, Coronel Xavier Chaves, Cristiano Otoni, Desterro de Melo, Desterro de Entre Rios, Dores de Campos, Entre Rios de Minas, Ibertioga, Ibituruna, Itaverava, Jeceaba, Lagoa Dourada, Lamim, Madre de Deus de Minas, Nazareno, Ouro Branco, Paiva, Piedade do Rio Grande, Piranga, Prado, Queluzito, Resende Costa, Ressaquinha, Rio Espera, Ritápolis, Santa Bárbara do Tugúrio, Santa Cruz de Minas, Santa Rita de Ibitipoca, Santana do Garambéu, Santana dos Motes, São Brás do Suaçuí, São João del-Rei, São Tiago, São Vicente de Minas, Senhora de Oliveira, Senhora dos Remédios e Tiradentes (CMSVM, 2010). Dos 51 municípios que compõem o consórcio, 13 pertencem à bacia do rio Paraopeba (Casa Grande, Congonhas, Conselheiro Lafaiete, Cristiano Otoni, Desterro de Entre Rios, Entre Rios de Minas, Itaverava, Jeceaba, Lagoa Dourada, Ouro Branco, Queluzito, Resende Costa e São Brás do Suaçuí), mas apenas um informou sobre a consorciação (Congonhas).

Coderi - O Consórcio de Desenvolvimento da Região dos Inconfidentes é formado pelos municípios de Ouro Preto, Mariana, Itabirito, Santa Bárbara e Catas Altas. O Consórcio tem o objetivo de fixar condições de cooperação mútua com o fim de promover o desenvolvimento sustentável regional, integrar as ações de preservação e revitalização ambiental, desenvolvimento socioeconômico estratégico, planejamento urbano e rural integrados, saneamento, ações educacionais, de ação social, saúde, esporte, turismo e preservação do patrimônio cultural artístico e natural regional. Outra finalidade é planejar e executar projetos e programas que visem o desenvolvimento regional sustentável, o aperfeiçoamento das gestões administrativas de seus consorciados e a formulação de políticas públicas regionais que venham beneficiar a população da Região dos Inconfidentes e municípios circunvizinhos (DOM-POP, 2010). Dos cinco municípios que compõem o consórcio, apenas um pertence à bacia do rio Paraopeba (Ouro Preto).

Circuito Verde - A Associação Circuito Verde-Trilha dos Bandeirantes é uma entidade civil sem fins lucrativos, legalmente constituída com estatuto próprio, que foi qualificada como Oscip em 2002. O circuito é formado pelas cidades de Betim, Conceição do Pará, Esmeraldas, Florestal, Itaúna, Juatuba, Pitangui, Ribeirão das Neves e São Gonçalo do Pará. Ela tem como objetivo promover a sinergia necessária que possibilita implementar ações integradas visando um desenvolvimento turístico ambientalmente correto, culturalmente respeitoso, economicamente viável e socialmente justo através do envolvimento da comunidade, da iniciativa privada e do setor público, estabelecendo parcerias em benefício do turismo local e regional (Circuito Verde, 2011). Dos nove municípios que compõem o arranjo intermunicipal, cinco pertencem à bacia do Rio Paraopeba (Betim, Esmeraldas, Florestal, Itaúna, Juatuba), mas apenas um informou sobre sua participação (Juatuba).

Granbel - A Associação dos municípios da Região Metropolitana de Belo Horizonte foi fundada em 1975 em Betim. Nasceu para ser o fórum de debates e decisões políticas capazes de manter a unidade da Região Metropolitana de Belo Horizonte e representar seus interesses comuns. A meta da atual administração é buscar a cooperação mútua entre os municípios, compartilhando soluções e contribuindo para a implementação de boas práticas administrativas (Granbel, 2011). Dos 34 dos municípios que participam da associação, 13 pertencem à 
bacia do Rio Paraopeba (Betim, Brumadinho, Contagem, Esmeraldas, Florestal, Ibirité, Igarapé, Itatiauçu, Juatuba, Mário Campus, Mateus Leme, Rio Manso e São Joaquim de Bicas), mas apenas um informou sobre sua participação no arranjo intermunicipal e um município não respondeu ao questionário (Itatiaiuçu).

\section{Motivações, funções e fatores que dificultam e facilitam a cooperação}

Questionados sobre os motivos que levaram os municípios a participar de consórcios, os representantes destacaram principalmente a falta de recursos para investimento, sobretudo para os pequenos municípios e com baixa arrecadação. O que consequentemente os leva a buscar redução de custos e economia, cooperação e fortalecimento para resolução de problemas, além da facilidade da gestão associada.

Os consórcios possibilitam aos municípios o desenvolvimento de políticas públicas com melhor custo-benefício. As prefeituras enfrentam os mais diversos problemas na administração desde a falta de recursos financeiros até a falta de profissionais capacitados para o desempenho de certas funções. Com isso, os municípios têm se utilizado dos consórcios públicos para suprirem essa deficiência para uma melhor resolução de suas demandas (Representante de Mateus Leme).

Outros motivos apontados para a articulação foram a busca de maior integração entre os municípios, a facilidade para as negociações de tratados municipais, a facilidade de organização. E, ainda, segundo o representante do município de Sete Lagoas, "as responsabilidades pelo desenvolvimento de ações e atividades de acordo com planejamento e diretrizes políticoadministrativas".

O representante público do município de Rio Manso destaca que os consórcios são "ferramentas na prestação de serviços de qualidade" que permitem a adoção de políticas com visão global, promover ações ligadas às áreas ambientais e melhorar as condições de sustentabilidade.

Para o representante de Felixlândia, o consorciamento é a melhor maneira de gerenciar e gerir as questões ambientais do município, além da possibilidade de captação de recursos. "Na área de resíduos sólidos exponencialmente fica muito mais barato, muito mais em conta trabalhar com outros municípios." Ainda com relação aos resíduos sólidos, outros representantes apontam a necessidade de buscar um local adequado para a destinação, considerando a ausência de área para construção de aterro no município; além da dificuldade de, sozinhos, gerenciar os resíduos de saúde. O representante de Curvelo, mais enfático, aponta que o maior motivador são as razões legais, pois sem a participação no consórcio não teria acesso à verba da implantação do aterro sanitário.

Mais relacionado à formação de consórcios na área da saúde, o representante do município de Pequi informa que ao se consorciar com outros municípios a prestação de serviço à população é ampliada. Outros representantes públicos acrescentam que é melhorada a qualidade e o atendimento aos serviços médicos e exames especializados. 
Ainda com relação aos motivos que levaram os municípios a participar de consórcios, 20 representantes não souberam responder essa questão.

Dos nove municípios que informaram não participar de nenhum consórcio, com relação aos motivos da não participação, um representante informou não haver nenhum motivo específico da não participação; outro disse que é por falta de contato e propostas; e o representante público acrescentou "não tivemos oportunidade, não teve uma oferta para nós ainda, alguma coisa que coubesse na realidade do município". Os demais não souberam informar as razões de não participação em consórcios.

Indagados sobre as funções de um consórcio, os representantes públicos destacaram, principalmente, o gerenciamento de questões comuns com vistas ao bem coletivo, partilha de investimentos; divisão de custos e tarefas. Para o representante do município de Brumadinho, "as principais funções de um consórcio são: a) representar os entes consorciados, defendendo interesses comuns; b) realizar o que os municípios, sozinhos, não teriam viabilidade técnica e econômica para fazê-lo".

Outras funções seriam a integração entre os municípios, buscando fortalecimento e apoio mútuo, compartilhamento de experiências e informações, com o intuito de melhorar a gestão e as políticas públicas municipais. "Dimensionar e diagnosticar o objeto de sua natureza, propondo ações conjuntas, prestando assessoria técnica e jurídica viabilizando ações modernas através de projetos e pesquisa de disponibilidade de recursos e parcerias, representando os segmentos consorciados" (Representante de Sarzedo).

Alguns representantes também destacam a importância da associação visando obtenção de mais apoio do governo. E, ainda, segundo o representante de Moeda, promover o desenvolvimento de uma determinada região através de parcerias.

No tocante à questão ambiental foi citado o gerenciamento do aterro, apoio técnico na busca de alternativas e melhorias ambientais, viabilização de fontes de recursos financeiros, capacitação de recursos humanos e implementação da gestão de recursos hídricos para recuperação da Bacia. Podendo ainda haver, segundo o representante do município de Contagem, promoção de educação ambiental, como trabalhos de educação ambiental nas escolas da bacia e obras de infraestrutura. Além da possibilidade de formação de convênios, pois a partir de um consórcio pode-se criar outros convênios, convênio com escolas, convênio com outros órgãos e entidades. Ainda com relação a quais seriam as principais funções de um consórcio, 11 representantes públicos não souberam responder essa questão.

Questionados sobre como se estruturam os consórcios para desempenhar suas atribuições (tarefas), os representantes públicos indicaram várias possibilidades. Entre as mencionadas estão contratação de funcionários (19 representantes), distribuição de ações entre os membros (17), terceirização de mão de obra (12), utilização de funcionários municipais (11), sendo citadas ainda outras possibilidades por três representantes (gráfico 3). 
Gráfico 3

Como os consórcios se estruturam para desempenhar suas funções

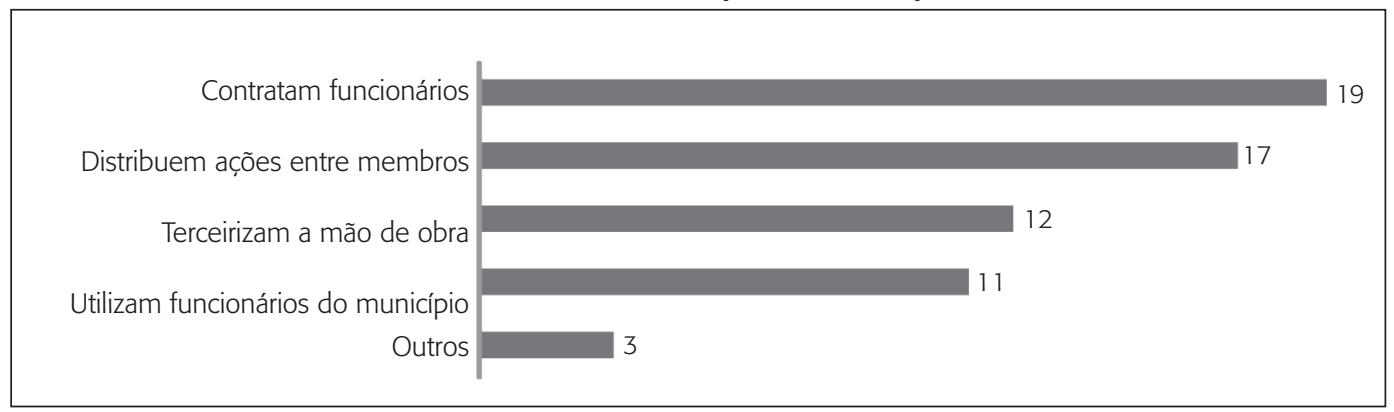

Fonte: Elaboração dos autores.

Questionados sobre quais seriam os fatores que dificultam a consolidação dos consórcios, os representantes públicos escolheram mais de uma opção da listagem, conforme ilustra o gráfico 4. A articulação entre os municípios foi o fator que obteve o maior número de indicações, ou seja, 32, o que corresponde a $26 \%$ do total. Em seguida vêm as dificuldades estruturais, ou seja, captação de recursos e apoio técnico, com 27 (22\%) das indicações; dificuldades de implementação de projetos, com 19 (15\%), e dificuldades internas de planejamento de organização, com 18 indicações (14\%). As dificuldades de articulação com o governo estadual e com as empresas (usuárias) e sociedade civil (ONGs) receberam 12 indicações (10\%) cada, enquanto outras dificuldades receberam cinco indicações (5\%).

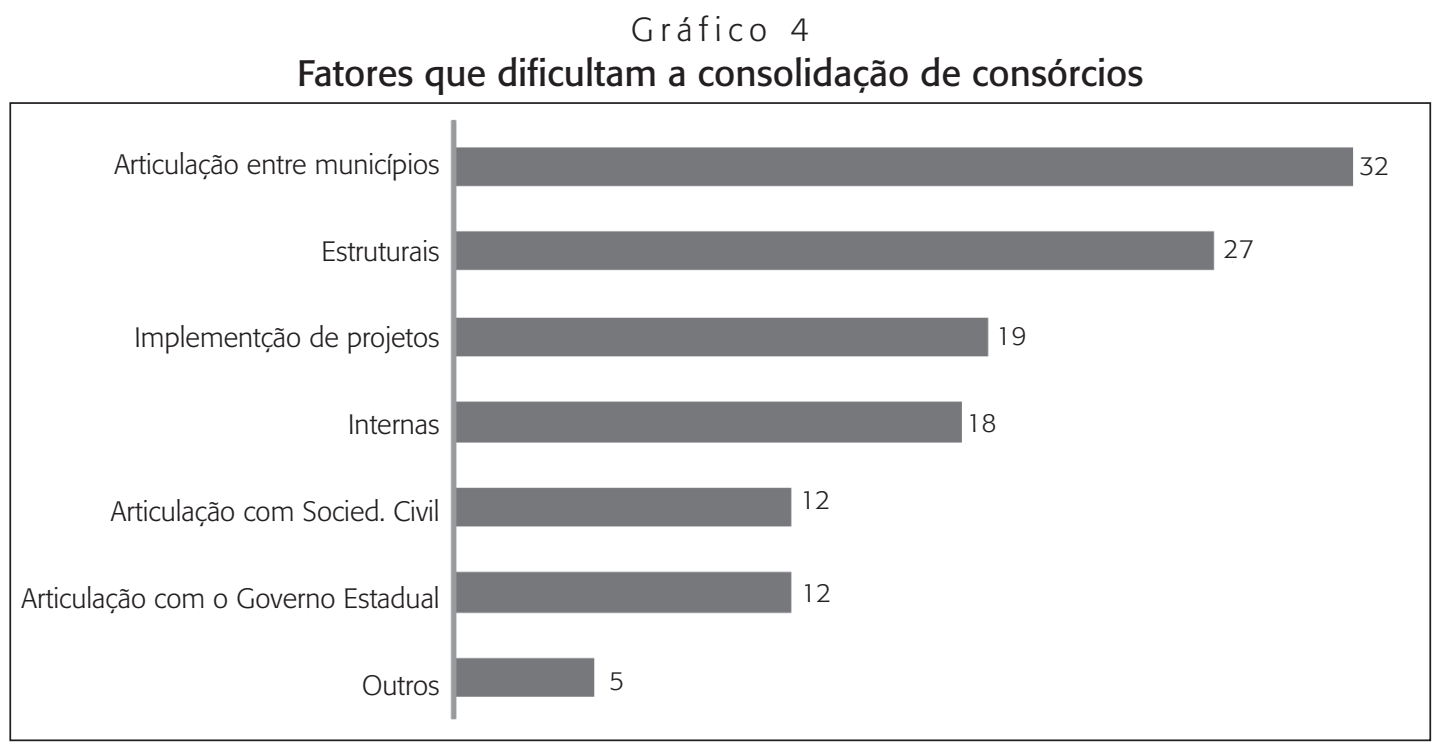

Fonte: Elaboração dos autores. 
Outros fatores citados foram a disponibilidade de tempo para participação, a falta de comunicação, a dificuldade de atendimento das necessidades, a falta de recursos financeiros e os interesses dos municípios não consorciados.

Os dados da pesquisa corroboram a explanação de Barros (1995), para quem a associação das variáveis legislação, organização, captação de recursos, apoio administrativo, apoio técnico e divulgação é a principal dificuldade estrutural e funcional dos consórcios.

\section{Facilitadores}

Com relação aos fatores facilitadores para a consolidação dos consórcios (gráfico 5), os representantes públicos também escolheram mais de uma opção na listagem. A cooperação municipal recebeu 30 indicações, ou seja, 34\% do total; seguida por facilidade de acesso a recursos, com 21 indicações (24\%); liderança unificada, com 17 (19\%); atualização permanente, com 13 indicações (15\%); e outros, com sete indicações (8\%).

$$
\text { Gráfico } 5
$$

\section{Fatores facilitadores para a consolidação do consórcio}

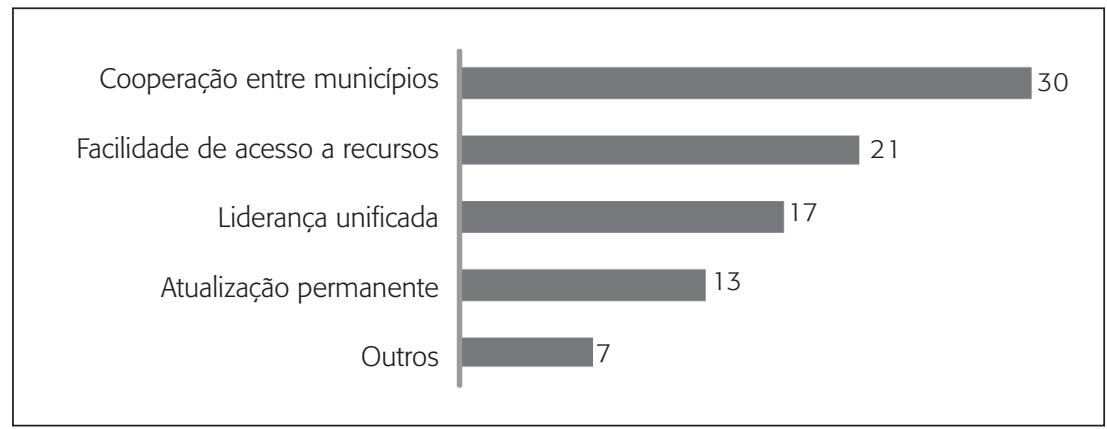

Fonte: Elaboração dos autores.

Os outros fatores destacados foram a unificação de interesses e objetivos comuns, bem como uma maior força para acessar os órgãos competentes. O representante de Felixlândia acrescenta a capacidade de gestão e a capacidade técnica para diagnóstico e implantação de ações. O representante de Caetanópolis aponta que os municípios consorciados devem possuir características e realidades parecidas, e justifica:

porque se você põe um município grande demais, uma cidade como, por exemplo, Sete Lagoas e Caetanópolis, ela não vai querer ficar e fazer um consórcio com a gente. Ela é muito maior, ela está mais no nível mais próximo da capital... aí teria que ser cidades todas mais ou menos do mesmo nível para que haja ali a captação de recursos, ideais e realidades (Representante de Caetanópolis). 
De acordo com o representante de Curvelo, um fator fundamental para um melhor funcionamento dos consórcios seria a criação de uma legislação que levasse os municípios a se consorciarem. Ele opina que "a coisa só vai acontecer através do dinheiro... por força de lei, você pode estar passivo de uma multa, não seria bem o medo da lei, mas o medo da multa... e, só vai ter acesso ao dinheiro se for através de consórcio".

Questionados sobre que tipo de ações devem ser implementadas no consórcio (gráfico 6), 34 representantes destacaram a busca por maiores recursos, obtendo $24 \%$ do total das indicações. A captação de investimentos externos e o desenvolvimento de parcerias com universidades receberam 27 indicações (19\%) cada. Em sequência, aparecem a melhoria da capacidade de gestão, com 26 indicações (18\%); a criação e/ou melhoria de um banco de dados, com 19 (13\%); e outras ações, com oito (6\%).

Gráfico 6

Tipos de ações que devem ser implementadas no consórcio

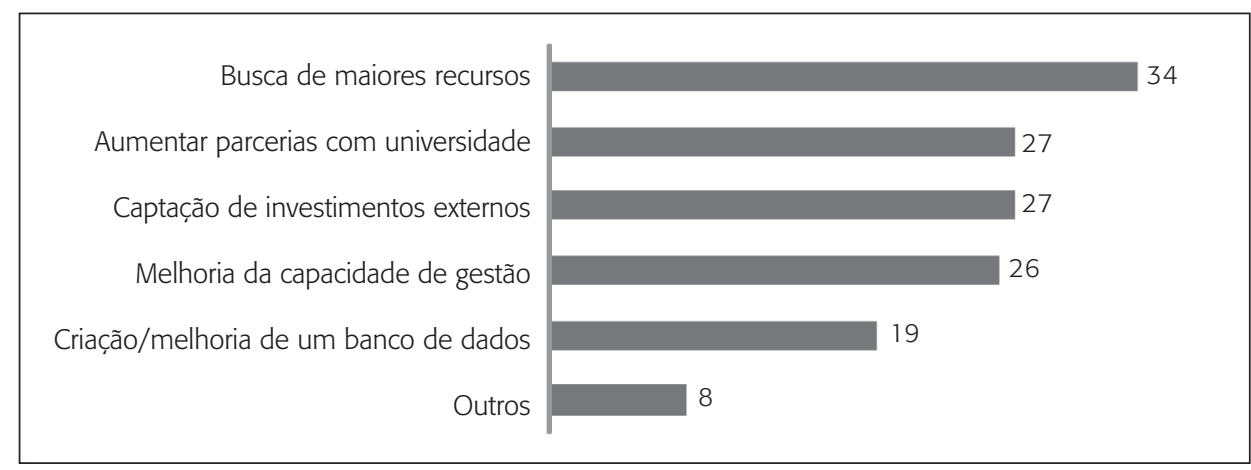

Fonte: Elaboração dos autores.

O representante de Curvelo destaca que várias dessas ações são importantes, mas a melhoria da capacidade de gestão deve ser o primeiro passo. A capacitação é importante, uma vez que buscar recursos sem possuir uma gestão apropriada, ou seja, a falta de planejamento e gerenciamento adequado, pode evidenciar um valor incorreto ou, o que seria pior, o desconhecimento dos recursos necessários.

A busca por recursos deve ser frequente, diz o representante de Contagem, pois, sem recurso, fica difícil para o consórcio executar suas tarefas, pagar funcionários e pagar contas, além de adquirir insumos básicos. A captação de investimentos externos é também uma das peculiaridades do consórcio para a sua existência, e uma de suas atribuições seria a criação do banco de dados.

No item outras ações, destacam-se: ajudar os municípios com recursos, aumento de parceria buscando maior adesão dos municípios, levar a sério os problemas de cada município e divulgar resultados alcançados. Diretamente relacionados à questão ambiental aparecem: criar equipe de monitoramento, promover a melhoria da qualidade ambiental e, segundo o 
representante de Ouro Branco, buscar o fortalecimento das ações visando à implementação dos Planos Municipais Participativos de Saneamento Básico Lei no 11.445/2007.

O representante do município de Crucilândia destaca ainda a necessidade de parceria com o setor educacional para divulgação em escolas, família, comunidade e, finalmente, governo municipal. Ele acredita que a inversão na abordagem (de baixo para cima), para sensibilização do trabalho, seria mais proveitosa e eficiente.

Os representantes, ao serem questionados sobre o que poderia ser feito para melhorar e/ou apoiar a cooperação intermunicipal, apontaram várias ações, que podem ser divididas em oito categorias, conforme ilustra o gráfico 7.

Dos fatores indicados pelos representantes que contribuem para a cooperação intermunicipal, o que obteve o maior número de indicações foi a divulgação, ou seja, uma comunicação mais eficaz, com 23\% do total. Segundo o representante de Mário Campos, deve haver maior divulgação nos municípios sobre o funcionamento dos consórcios, ou seja, estrutura, organização e ações desenvolvidas, bem como maior divulgação das reuniões e fóruns. Ele diz, também, que a adoção destas medidas poderia servir de incentivo aos municípios que ainda não participam do consórcio.

\section{Gráfico 7}

Fatores para melhorar e/ou apoiar a cooperação intermunicipal

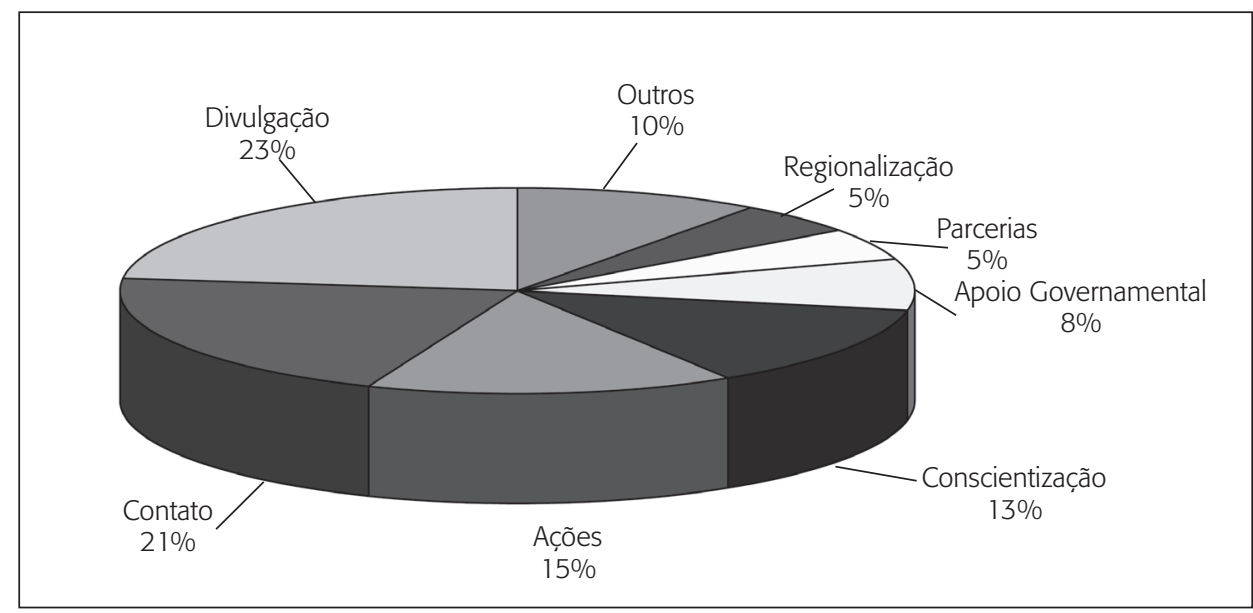

Fonte: Elaboração dos autores.

O representante do município de Paraopeba sugere a realização de audiências públicas para evidenciar as oportunidades que os municípios estão deixando de ter ou conseguir, e para destacar quais projetos poderiam ser compartilhados entre os municípios da bacia.

Acerca da questão ambiental, o representante de Brumadinho afirma haver necessidade de se ampliar a divulgação do consórcio e dos princípios da gestão das águas (bacia hidrográfica como unidade de planejamento etc.) para proporcionar uma internalização desses 
princípios entre os entes do consórcio. O representante de Igarapé sugeriu que também é importante buscar uma comunicação mais intensa com a população da bacia, promovendo divulgação e transparência das ações.

O fator "contato" obteve $21 \%$ das indicações dos representantes, que alegam ser preciso estreitar as relações entre os consórcios e os municípios através da presença do corpo gestor e técnico do consórcio no município, realizando palestras, ações, atividades variadas, buscando apoio na área educacional e de saúde. O representante de Ouro Preto igualmente aponta a necessidade de reuniões mais frequentes também no gerenciamento de recursos hídricos e acrescenta que devem ser realizadas "com todos os municípios da bacia, consorciados ou não".

A importância com relação às ações do consórcio aparece logo em seguida, com 15\% das indicações dos representantes públicos, que citaram a necessidade de ações concretas mais voltadas aos municípios e comunidades.

Segundo Barros (1995), os consórcios devem compreender que a qualidade de vida da população não pode abdicar de determinados elementos, como saúde, saneamento, segurança, equilíbrio ecológico etc. E a ausência de um determinado elemento é a origem das necessidades e reivindicações da população, e são essas que colocam em movimento o objeto do consórcio. Portanto, se as necessidades da população não mobilizarem os projetos, o consórcio ficará paralisado ou funcionará mal, podendo, inclusive, extinguir-se.

Visando aumentar a cooperação, 13\% dos representantes indicaram a necessidade de se desenvolver a conscientização dos gestores públicos para com a causa do consórcio e buscar uma participação mais efetiva, bem como fomentar a ideia de trabalhos em conjunto. Se não houver o discernimento por parte dos gestores públicos e ambientais, afirma o representante do município de Jeceaba, quanto à importância do consórcio como órgão responsável pela gestão das águas da bacia, dificilmente se terá uma participação comprometida e efetiva. É preciso envolver os municípios nas questões referentes ao rio Paraopeba nos seus territórios, mas de forma coordenada com vistas à melhoria de toda a bacia, estabelecendo prazos e metas (Representante de Igarapé).

O apoio governamental também aparece com 8\% das indicações. Para os representantes, é preciso mais apoio do governo, principalmente o estadual, aos consórcios, através do estabelecimento de parcerias com órgãos do governo e incremento de recursos. Com esse apoio, afirma o representante de Contagem, com certeza os consórcios teriam uma melhoria. Citando a experiência do Consórcio da Pampulha, ele esclarece que o problema é que em algumas situações o consórcio não dispõe de recurso suficiente para realizar toda a obra como necessário,

aí você muda toda uma concepção de projeto, transforma a obra em uma outra obra diferente daquele objeto inicial para fazer a obra conforme recurso. E quando se tem recurso aí você faz a obra como ela realmente deve ser. Então, se você tiver um apoio maior do poder estadual e quem sabe do poder federal, com certeza você terá um fortalecimento do consórcio (Representante de Contagem). 
Aqui também ocorre identidade com as afirmações de Barros (1995) de que o estado possui a função primordial de estimular os consórcios mediante políticas consistentes e duradouras, bem como a função complementar de colaborar com os mesmos financeiramente. Ao abdicar dessas funções, o estado causa alterações significativas na capacidade de os consórcios definirem e programarem seus compromissos prioritários "para com políticas públicas básicas e políticas sociais, não apenas de subtrair sua eficácia virtual, mas principalmente determinando sua falência irremediável" (Barros, 1995:82).

Com relação à regionalização das ações e dos eventos, que aparece em 5\% das indicações, os representantes abordaram especificamente a situação da bacia. Segundo o representante de Brumadinho, devem-se implantar escritórios regionais no Alto e Baixo Paraopeba, uma vez que o médio Paraopeba já possui, com o objetivo de dar maior suporte aos municípios das respectivas regiões. Para o representante de Ouro Branco, os eventos devem ser regionais (alta, média e baixa bacia) e "um geral para apresentar os resultados alcançados em um período predefinido pelos participantes do Cibapar".

A busca de parcerias também apareceu como fator de fomento à cooperação, com 5\% das indicações dos representantes públicos, ou seja, desenvolver parcerias com empresas privadas, organizações não governamentais e universidades.

As outras indicações (10\%) foram integração política, comunhão de ideias, legislação e recursos, como esclarece o representante de Curvelo:

Essa cooperação, ela só vai acontecer primeiro por força de lei, porque o desnível também entre os administradores é enorme; tem prefeito que é analfabeto; nós temos deputado federal analfabeto, né... então, tem prefeito analfabeto. Quase todos, ainda que estudados e com diplomas, desconhecem a lei, quase todos são extremamente mal assessorados, e algum que tem uma assessoria, às vezes não escuta a assessoria. Então, o que poderia ser feito para melhorar a cooperação: primeiro, lei para forçar esses caras, querendo ou não a se consorciar. Segundo, restringir o máximo possível o acesso à verba via consórcio, porque aí, mais uma vez, a parte mais sensível do corpo humano é o bolso, então é por aí também. E um ganho disso é poder contratar técnicos, porque você ter, por exemplo, um engenheiro, qualquer que seja a especialização ou um biólogo para cada prefeitura vai ser difícil, via consórcio é mais fácil e mais barato. Então é dinheiro e lei (Representante de Curvelo).

\section{Considerações finais}

O processo de reforma política e administrativa ampliou as possibilidades de gestão, modificando assim o papel do Estado, que vem deixando de ser um executor de serviços e obras para ser um gestor. Entretanto, considerando as limitações de recursos financeiros, humanos e estruturais enfrentadas por muitos municípios e a busca de alternativas de gestão, os governos locais vêm firmando parcerias para prover os serviços públicos, sociais e científicos, a fim de torná-los mais ágeis e eficazes no atendimento das necessidades da população. 
As redes de cooperação desenvolvem um novo modelo de gestão de políticas públicas a partir da ampliação de oferta de serviços, flexibilização da contratação de pessoal, colaboração técnica e realização conjunta de obras, serviços e atividades temporárias ou permanentes. Elas surgem como uma estrutura capaz de demandar mais eficientemente os recursos, bem como possibilitar a ampliação da capacidade política dos municípios a eles vinculados. O fato de se constituírem em unidades territoriais de gestão facilita a articulação intermunicipal, pois os municípios transferem a um órgão de governança somente uma parte de sua autonomia, permitindo a gestão de um recurso que não lhes é exclusivo, mas compartilhado por uma comunidade mais ampla, que de outra forma poderia ser prejudicada pela inexistência de um órgão com uma perspectiva mais ampla.

$\mathrm{Na}$ análise das respostas dos representantes públicos evidencia-se uma abertura por parte dos municípios à participação em consórcios, considerando que $83 \%$ fazem parte de um ou mais tipos de arranjos intermunicipais. Detectou-se que as principais motivações para participar são a falta de recursos para investimento, a busca por cooperação visando redução de custos e economia e o fortalecimento mútuo por meio da gestão associada.

Apesar da abertura à formação dos arranjos intermunicipais, os representantes destacaram a necessidade de ações para melhorar e/ou apoiar a cooperação entre os municípios. Foram destacados, principalmente, a necessidade de divulgação mais eficaz, o estreitamento dos laços entre municípios e os arranjos formados. Sendo preciso buscar maior envolvimento visando aumentar a conscientização e o comprometimento por parte da população e dos representantes públicos.

\section{Referências}

AGÊNCIA METROPOLITANA. Região Metropolitana de Belo Horizonte. 2011. Disponível em: <www. agenciarmbh.mg.gov.br>. Acesso em: 6 mar. 2011.

AGÊNCIA MINAS. Notícias do Governo do Estado de Minas Gerais. Associativismo microrregional será fortalecido em Minas. 20 out. 2005. Disponível em: <www.agenciaminas.mg.gov.br>. Acesso em: 7 mar. 2011.

ALMEIDA, Josimar R. et al. Política e planejamento ambiental. 3. ed. rev. e atual., 3. reimpr. Rio de Janeiro: Thex, 2009.

AMALPA. Associação dos Municípios da Microrregião do Alto Paraopeba. Apresentação. Disponível em: <www.amalpa.org.br>. Acesso em: 6 mar. 2011.

AMAV. Associação dos Municípios da Microrregião do Alto Rio das Velhas. Conheça a Amav. Disponível em: <www.amav.mg.gov.br>. Acesso em: 6 mar. 2011.

BARROS, Pedro M. Consórcio intermunicipal: ferramenta para o desenvolvimento regional. São Paulo: Alfa Omega, 1995. 
BEST, Nina J. Cooperação e multi-level governance: o caso do Grande Recife Consórcio de Transporte Metropolitano. Dissertação (mestrado) - Escola de Administração de Empresas de São Paulo, Fundação Getulio Vargas, 2011.

BRASIL. Constituição da República Federativa do Brasil. 1988. Brasília: Senado, 1988.

BRASIL. Ministério da Administração Federal e da Reforma do Estado. Plano diretor da reforma do Estado. Brasília. 1995. Disponível em: <www.bresserpereira.org.br>. Acesso em: 2 nov. 2010.

BRASIL. Secretaria de Coordenação Política e Assuntos Institucionais. Lei de consórcios públicos nº 11.107. Brasília: 2005.

BRESSER-PEREIRA, Luiz C. Gestão do setor público: estratégia e estrutura para um novo Estado. In: BRESSER-PEREIRA, Luiz C.; SPINK, Peter K. Reforma do Estado e administração pública gerencial. Tradução de Carolina Andrade. Rio de Janeiro: Editora Fundação Getulio Vargas, 1998. p. 21-38.

BUCCI, Maria P. D. Gestão democrática da cidade. In: DALLARI, Adilson (Org.). Estatuto da cidade. São Paulo: Malheiros, 2002. p. 322-341.

CALDAS, Eduardo L. Formação de agendas governamentais locais: o caso dos consórcios intermunicipais. Tese (doutorado em ciência política) — Departamento de Ciência Política, Faculdade de Filosofia, Letras e Ciências Humanas, Universidade de São Paulo, 2007.

CARVALHO, Vinícius C. Consórcio intermunicipal e cooperação federativa: desafios para a gestão ambiental conjunta na bacia do Jiquiricá (Bahia). Dissertação (mestrado em desenvolvimento sustentável) — Universidade de Brasília, Brasília, 2007.

CEPAM - INFORMATIVO. Consórcio: uma forma de cooperação intermunicipal. São Paulo: Fundação Prefeito Faria Lima - Cepam; Unidade de Políticas Públicas - UPP, v.1, n. 2, 2001.

CIRCUITO VERDE. Associação Circuito Verde-Trilha dos Bandeirantes. O circuito. Disponível em: <www.circuitoverde.org.br>. Acesso em: 15 mar. 2011.

CISMEP. Consórcio Intermunicipal de Saúde do Médio Paraopeba. Institucional. Disponível em: <www.cismep.com.br>. Acesso em: 6 mar. 2011.

CMB. Câmara Municipal de Betim. Lei no 4.858, de 8 de setembro de 2009. Autoriza o poder executivo a participar do Consórcio Médio Paraopebano de Resíduos Sólidos - Comparesolurb. Disponível em: <www.camarabetim.mg.gov.br>. Acesso em: 6 mar. 2011.

CMCL. Câmara Municipal de Conselheiro Lafaiete. Lei no 4.783, de 1o de dezembro de 2005. Autoriza o município de Conselheiro Lafaiete a constituir Consórcio Intermunicipal de Tratamento de Resíduos Sólidos - Ecotres, 2005. Disponível em: <www.camaraconselheirolafaiete.mg.gov.br>. Acesso em: 7 mar. 2011.

CMSVM. Câmara Municipal de São Vicente de Minas. Lei no 1.476/2010. Autoriza o município de São Vicente de Minas a participar de consórcios públicos e dá outras providências. Disponível em: <http://camarasvm.hd1.com.br/leis2010/LEI-1476-2010.PDF>. Acesso em: 6 mar. 2011.

CODAP. Revista Codap - Veículo informativo do Consórcio Público para Desenvolvimento do Alto Paraopeba. Maio 2010. Disponível em: <www.pqn.com.br>. Acesso em: 6 mar. 2011. 
COMITÊ (CBH) E CONSÓRCIO INTERMUNICIPAL (CIBAPAR) DA BACIA HIDROGRÁFICA DO RIO PARAOPEBA. Disponível em: <www.aguasdoparaopeba.org.br>. Acesso em: fev. 2010 a abr. 2011.

COMLAGO. Consórcio dos Municípios do Lago Três Marias. Organograma. 2009. Disponível em: $<$ www.comlago.org.br/site/index.php?page=municipios $>$. Acesso em: jun. 2011.

COSENS-MG. Colegiado dos Consórcios de Secretários Executivos do Estado de Minas Gerais. Perfil dos consórcios intermunicipais de saúde de Minas Gerais. 2010. Disponível em: <www.cosecsmg. org.br>. Acesso em: 6 mar. 2011.

CRBP. Consórcio de Recuperação da Bacia da Pampulha. Estatuto da Associação Civil Comunitária da Bacia da Pampulha. 2003.

CRUZ, Maria do C. et al. Consórcios intermunicipais de desenvolvimento: mudando para sobreviver. In: CONGRESSO NACIONAL DE ADMINISTRAÇÃO PÚBLICA, 2., 2009, Brasília. Anais... Brasília: Repositório Digital Saberes em Gestão Pública, 2009. p. 1-29. Disponível em: <www.cepam.sp.gov. br/arquivos/artigos/5_Consorcio_site.pdf>. Acesso em: 2 jul. 2012.

DIEGUEZ, Rodrigo C. Carvalho. Autonomia, accountability e coesão interna: uma análise políticoinstitucional de consórcios intermunicipais. Dissertação (mestrado) — Departamento de Sociologia e Política, Pontifícia Universidade Católica do Rio de Janeiro, Rio de Janeiro, 2011.

DINIZ, Danusa F. C. Consórcio intermunicipal: estratégias competitivas e colaborativas do Civarc no norte pioneiro do Paran. Curitiba, 2009. Dissertação (mestrado em administração) — Setor de Ciências Sociais Aplicadas, Universidade Federal do Paraná, Curitiba, 2009.

DOM-POP. Diário Oficial do Município da Prefeitura de Ouro Preto. Lei $n^{\circ} 571$. Ratifica o Protocolo de Intenções do Consórcio de Desenvolvimento da Região dos Inconfidentes — Coderi. Ouro Preto, ano II, no 128, 29 jul. 2010. Disponível em: <www.prefeituradeouropreto.com.br>. Acesso em: 6 mar. 2011.

FERNANDES, Antônio E. F. Políticas públicas e a gestão sócio-ambiental: paradigmas e proposições do Comdema - Conselho Municipal de Defesa do Meio Ambiente de Lavras (MG). Revista Gestão Universitária. 7 out. 2009. Disponível em: <www.gestaouniversitaria.com.br>. Acesso em: 10 fev. 2010.

GRANBEL. Associação dos municípios da RMBH. Fundação. Disponível em: <www.granbel.com. br>. Acesso em: 15 mar. 2011.

IBGE. Instituto Brasileiro de Geografia e Estatística. Contagem da população 2007 - 21 dez 2007. Disponível em: <www.ibge.gov.br/home/estatistica/populacao/contagem2007/>. Acesso: 6 mar 2011.

IBGE. Instituto Brasileiro de Geografia e Estatística. O Brasil município por município. 2010. Disponível em: <www.ibge.gov.br>. Acesso em: 6 mar. 2011.

IBGE. Instituto Brasileiro de Geografia e Estatística. Perfil dos municípios brasileiros. 2008. Disponível em: <www.ibge.gov.br>. Acesso em: 30 dez. 2009.

IBGE. Instituto Brasileiro de Geografia e Estatística. Perfil dos municípios brasileiros — meio ambiente. 2002. Disponível em: <www.ibge.gov.br>. Acesso em: 30 jan. 2011. 
IGAM. Instituto Mineiro de Gestão das Águas. Comitês de bacias hidrográficas: unidades de planejamento. 2011. Disponível em: <www.igam.mg.gov.br>. Acesso em: jun. 2011.

JACOBI, Pedro R. Governança da água no Brasil. IN: RIBEIRO, Wagner Costa (Org.). Governança da água no Brasil: uma visão interdisciplinar. São Paulo: Annablume; Fapesp; CNPq, 2009. p. 35-59.

JUNQUEIRA, Ana T. M. Consórcio Intermunicipal, um instrumento de ação. Revista Cepam, São Paulo, v. 1, n. 2, p. 29-35, abr./jun. 1990.

LACZYNSKI, Patricia. Políticas redistributivas e a redução das desigualdades: a contribuição potencial dos consórcios intermunicipais. Tese (doutorado) — Escola de Administração de Empresas, Fundação Getulio Vargas, São Paulo, 2012.

MATIAS-PEREIRA, José. Governança no setor público. São Paulo: Atlas, 2010.

PRATES, Angelo M. Q. Os consórcios públicos municipais no Brasil e a experiência europeia: alguns apontamentos para o desenvolvimento local. In: CONGRESSO CONSAD DE GESTÃO PÚBLICA, III, 2010, Brasília. Disponível em: <www.consad.org.br/>. Acesso em: 14 nov. 2010.

RAMALHO, Ana Maria F. Autonomia e cooperação: os desafios da gestão metropolitana. Tese (doutorado) - Centro de Artes e Comunicação, Universidade Federal de Pernambuco, Recife, 2009.

RIBEIRO, Hermínia; FARIA, Raquel. A cooperação intermunicipal portuguesa. Centro de Estudos sobre África e do Desenvolvimento. Instituto Superior de Economia e Gestão da Universidade Técnica de Lisboa. Lisboa, 2009. Disponível em: <www.iseg.utl.pt/cesa >. Acesso em: 26 mar. 2011.

SANTOS, M. G. Políticas públicas: contribuições para o debate. In: KANAANE, Roberto; FIEL FILHO, Alécio; FERREIRA, Maria das Graças. Gestão pública: planejamento, processo, sistemas de informação e pessoas. São Paulo: Atlas, 2010. p. 3-15.

STRELEC, Thamara C. Desafios da adaptação institucional: um estudo do impacto da Lei de Consórcios Públicos no estado de São Paulo. Dissertação (mestrado) - Escola de Administração de Empresas de São Paulo, Fundação Getulio Vargas, 2011.

TATAGIBA, Luciana. Os conselheiros gestores e a democratização das políticas públicas. In: DAGNINO, Evelina (Org.). Sociedade civil e espaços públicos no Brasil. Rio de Janeiro: Paz e Terra, 2002. p. 47-103.

WILSON, Robert H.; SPINK, Peter K.; WARD, Peter M. Governança metropolitana nas Américas. Cadernos Metrópole (PUC/SP), São Paulo, v. 13, n. 25, p. 15-44, jan./jun. 2011.

XAVIER, Beatriz O. Cidades e globalização: geminar urbanidades, solidarizar os espaços. In: CONGRESSO PORTUGUÊS DE SOCIOLOGIA, 4., 2000, Coimbra. Anais... Lisboa: Associação Portuguesa de Sociologia. Disponível em: <www.aps.pt>. Acesso em: 29 mar. 2011.

Fernanda Matos é mestre em turismo e meio ambiente pelo Centro Universitário UNA/MG. E-mail: fcmatobh@gmail.com.

Reinaldo Dias é professor do Centro de Ciências Sociais e Aplicadas (CCSA) da Universidade Presbiteriana Mackenzie (UPM/SP). E-mail: reinaldo.dias@mackenzie.br. 